\title{
Amyotrophic lateral sclerosis: A global threat with a possible difference in risk across ethnicities
}

Giancarlo Logroscino, MD, PhD; and Carmel Armon, MD, MHS

\section{What was the study trying to explain about ALS?}

Amyotrophic lateral sclerosis (ALS, Lou Gehrig's disease) is a progressive disease in which patients' muscles weaken and shrivel away. The disease takes patients' lives on the average 3 years after the first symptoms of weakness appear. Most often, this happens when the breathing muscles are unable to do their job. Sometimes patients choose to extend their lives by being connected to a breathing machine. The cause of most cases of ALS is unknown. A small number of cases occur within families, but over $90 \%$ occur randomly. ${ }^{1}$ Some previous studies have suggested that ethnicity might be one risk factor that determines who develops ALS, but others have suggested that this is not important. In this issue of Neurology, Cronin and colleagues ${ }^{2}$ explain what is known about the role of ethnic origin as a risk factor for development of ALS.

\section{How did the authors try to answer this question?}

The authors reviewed studies published in a 40-year period (1966 through 2006) that evaluated how often ALS appears in different geographic areas and different ethnic groups. The authors found 61 papers, but only 45 had good information on how often the disease is seen in different areas, including numbers called "incidence" and "prevalence."

"Incidence" is the number of new patients who develop disease each year divided by the number of people in the group (population) being studied. For people living in the United States and Europe, the incidence of ALS is approximately 2 per 100,000 people per year. However, the incidence of ALS increases as we get older, and for the 45- to 75year-old age group, it is closer to 5 per 100,000 people per year.
"Prevalence" is how many people in a group (population) have the disease at any given point in time divided by the number of people in the group. Unfortunately, there were very few studies from outside Europe and North America (only eight), and the quality of the studies was uneven. Most of the high-quality studies were conducted in Europe and North America (except for one in Japan and one in Uruguay). Many of the studies did not have enough information to compare results with other studies. This limits the ability to perform the comparisons needed to answer the authors' main question.

\section{What did they find?}

The main finding of the authors is that incidence appears to be lower among African, Asian, and Hispanic populations compared with Caucasians. However, the authors are not sure if that is a correct conclusion because of the limitations in the data. The main concern is whether all patients who developed ALS had the same chance of being counted, regardless of when or where the study was done or of the patients' ethnic origin. The authors are proposing that a large, well-designed study conducted in a racially mixed population might be needed to get a better answer to this question.

\section{Can we get better answers to this question?}

This is not easy to do. For example, if there were only two ethnic groups and one was four times more common than the other, then about 10 million individuals would need to be followed for 5 years to be able to detect with reasonable certainty a $25 \%$ difference between the groups in incidence of ALS. The only realistic way that this might be done in the United States is through a thorough effort across several states that have a racially diverse population. Alternatively, an effort across many nations could be done, using methods that would ensure that all patients who developed ALS in the populations studied had an equal chance of coming to the attention of the researchers.

\section{Why is this an important issue?} If ethnic differences in the risk of developing ALS were confirmed, this might provide clues as to what causes the disease and give focus to more research. Ethnic differences in ALS occurrence may suggest that there are different risk factors (environmental or genetic) across different ethnic groups. Ethnic differences in health may be due to socioeconomic, cultural, and religious factors. $^{3}$ These factors may determine differences in lifestyles. Some behaviors could be changed, such as smoking $^{1}$ or diet. The use of specific toxic or poisonous substances may also lead to an increased frequency of a disease in a specific ethnic group. On the other hand, differences in disease incidence may be due to the presence of different sets of genes in different ethnic groups. It is important to find as many clues as possible to identify what places people at risk for developing ALS because we do not know what causes the most common form of the disease. Careful studies in different ethnic groups might give us clues to both environmental and genetic risk factors for ALS.

\section{References}

1. Armon C. An evidence-based medicine approach to the evaluation of the role of exogenous risk factors in sporadic amyotrophic lateral sclerosis. Neuroepidemiology 2003;22 217-228.

2. Cronin S, Hardiman O, Traynor BJ. Ethnic variation in the incidence of ALS: a systematic review. Neurology 2007;68:1002-1007.

3. Pearce N, Foliaki S, Sporle A, Cunningham C. Genetics, race, ethnicity, and health. Br Med J 2004;328:1070-1072. 
Amyotrophic lateral sclerosis (ALS) is a disease in which the patient's muscles gradually weaken and deteriorate, ${ }^{1}$ and this leads to death. ALS usually begins in one region of the body and spreads to adjacent regions until the entire body is involved. As the muscles waste away, they often become stiff (spastic). The disease is different in each patient. ALS also affects the muscles responsible for speaking, swallowing, and breathing. Unless ALS patients choose to receive permanent mechanical breathing support, patients die when the muscles used for breathing no longer work. This happens on the average 3 years after the appearance of the first signs of weakness.

The reason why muscles shrivel away and stiffen in ALS is that there is gradual loss of the two types of nerve cells known as motor neurons, which make the muscles work (figure). The first type, or lower motor neurons, are found in two areas: in the spinal cord, where they are connected directly to the limb and spinal muscles, including the breathing muscles; and in the lower part of the brain (brainstem), where they are connected directly to muscles of the face, mouth, and throat, including muscles that control speech and swallowing. The muscles need the connection to lower motor neurons, not just to be able to do their job but also to live. Therefore, as lower motor neurons die and the muscles are no longer connected to those lower motor neurons, they also weaken, atrophy, and die. The second type of motor neuron, the upper motor neuron, is found in the brain. It is connected directly to the lower motor neurons and tells them what to do. As upper motor neurons die, they exert less control over the lower motor neurons; this results in the tendency of the muscles to stiffen. Although ALS presents as a disease of muscle loss, it is caused by the loss of the nerves that are connected to those muscles. For this reason, another name for ALS is "motor neuron disease."

ALS affects adults, and the risk of developing ALS increases as one gets older.

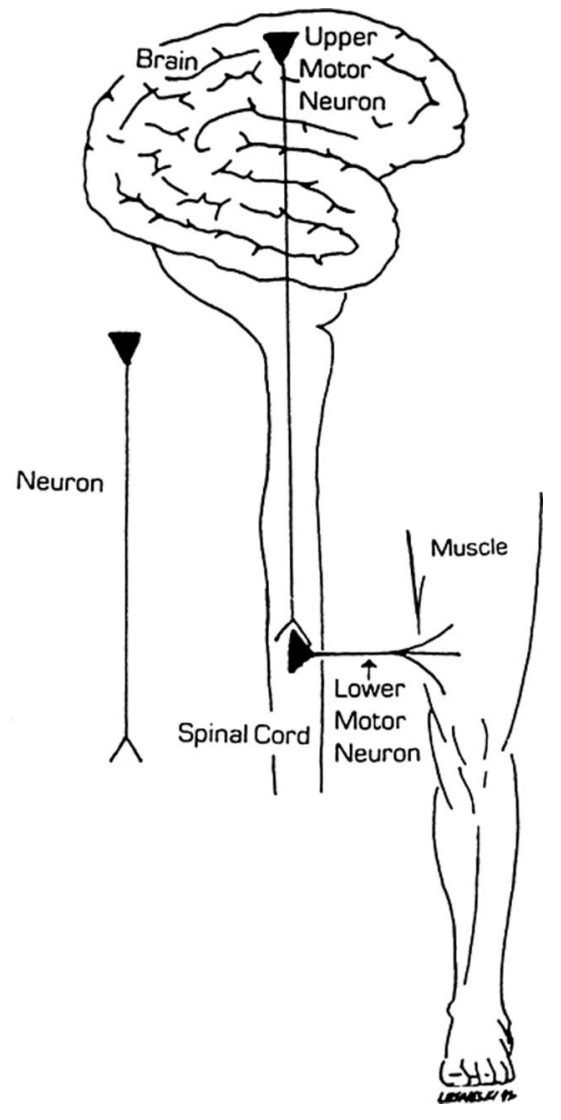

Figure. Diagram of a motor neuron (left) and of the locations and connections of representative upper and lower motor neurons (right). Figure drawn by Lee Lesneski, RN; reproduced from Armon. ${ }^{1}$

Men are affected more frequently than women. Of every 1 million adults age 18 or older, between 30 and 40 will develop ALS each year. It is estimated that in 2002, approximately 1 in every 350 men or 450 women who died in the United States died of ALS. ${ }^{2}$ About 1 in 20 ALS patients have or have had blood relatives with the disease, and this is referred to as the "familial" form of ALS. Over $90 \%$ are considered to have the "sporadic" or randomly occurring form of the disease. Its causes are not known. Common symptoms of the disease include weakness, muscle cramps, difficulties with speech and swallowing, unsteadiness, stiffness (spasticity), twitch- ing muscles, loss of muscle bulk (atrophy), foot drop, and breathing difficulties. In addition, patients may experience depression or periods of laughing and crying that are not under their control and seem out of proportion to or unconnected to the underlying emotions. There may be changes in the ability to think, usually with trouble in planning and sequencing abilities, and, less commonly, seeming to not care about the impact of the disease on oneself and one's loved ones. Memory tends not to be affected.

As the precise causes of ALS are unknown, little can be done to prevent it. Smoking is the best established risk factor for the disease and should be avoided. It is also a major risk factor for the leading causes of death in the developed world: heart disease, some forms of cancer, and stroke.

Treatment of ALS is accomplished best using a team approach. There is one approved medication for the disease-riluzole - that has been shown to extend life by 2 to 3 months. Education about the disease helps patients and their families to feel more in control as the disease progresses. There are many sources of good information for patients ${ }^{1,2-5}$ and many centers dedicated to caring for them throughout the world. ${ }^{6}$

The text of this "Patient Page-About $A L S^{\prime \prime}$ is modified from Armon. ${ }^{1}$

\section{References}

1. Armon C. ALS 1996 and beyond: new hopes and challenges. A manual for patients, families, and friends, 3rd ed. English and Spanish versions. 2000. www.llu.edu/llumc/ neurosciences/als/

2. Armon C. Sports and trauma in amyotrophic lateral sclerosis revisited. J Neurol Sci. Special Issue on Environmental Neurology, Román $\mathrm{G}$, editor. In press.

3. NINDS amyotrophic lateral sclerosis information page. English and Spanish. http://www.ninds.nih.gov/disorders/amyotro phiclateralsclerosis/amyotrophiclateralscle rosis.htm

4. Amyotrophic Lateral Sclerosis Association (ALSA). www.alsa.org

5. Muscular Dystrophy Association. www. mda.org

6. World Federation of Neurology Research Group on Motor Neuron Diseases. Listing of ALS clinics and centers. http://www.wfnals. org/clinics/index.html 


\section{Neurology}

\section{Amyotrophic lateral sclerosis: A global threat with a possible difference in risk across ethnicities}

Giancarlo Logroscino and Carmel Armon

Neurology 2007;68;E17

DOI 10.1212/01.wnl.0000260229.42772.a6

\section{This information is current as of March 26, 2007}

\section{Updated Information \&} Services

References

Permissions \& Licensing

Reprints including high resolution figures, can be found at: http://n.neurology.org/content/68/13/E17.full

This article cites 3 articles, 2 of which you can access for free at: http://n.neurology.org/content/68/13/E17.full\#ref-list-1

Information about reproducing this article in parts (figures,tables) or in its entirety can be found online at:

http://www.neurology.org/about/about_the_journal\#permissions

Information about ordering reprints can be found online: http://n.neurology.org/subscribers/advertise

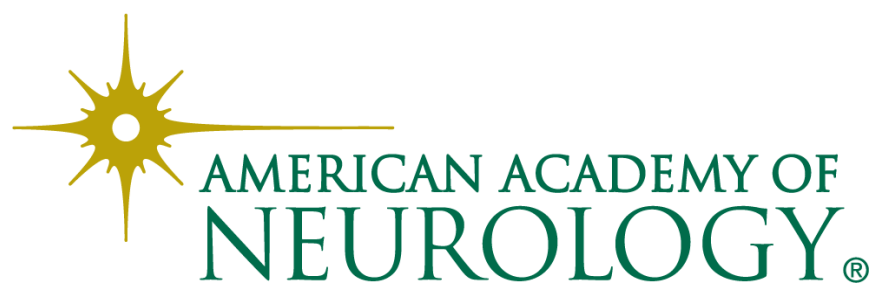

